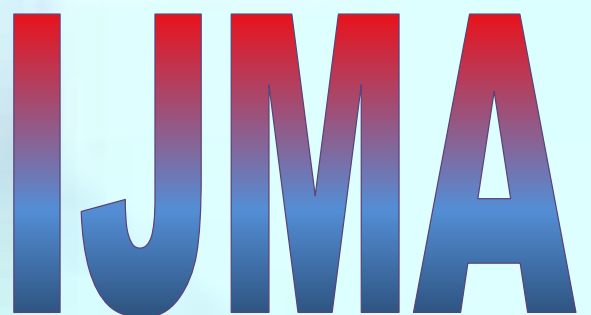

INTERNATIONAL

Journal of MEdical

\section{ARTS}

Volume 3, Issue 1 (Winter 2021)

http://ijma.journals.ekb.eg/

Print ISSN: 2636-4174

Online ISSN: 2682-3780

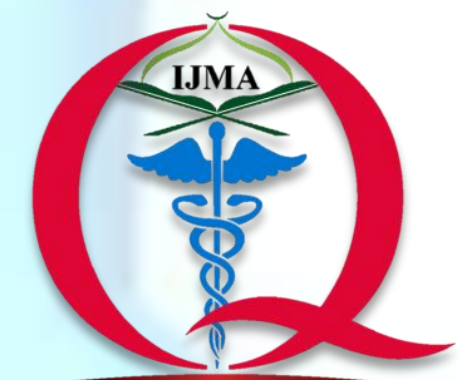

International Jounnal of Medical Arts

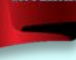



International Journal of Medical Arts 2021; 3 [1]: 905-912.

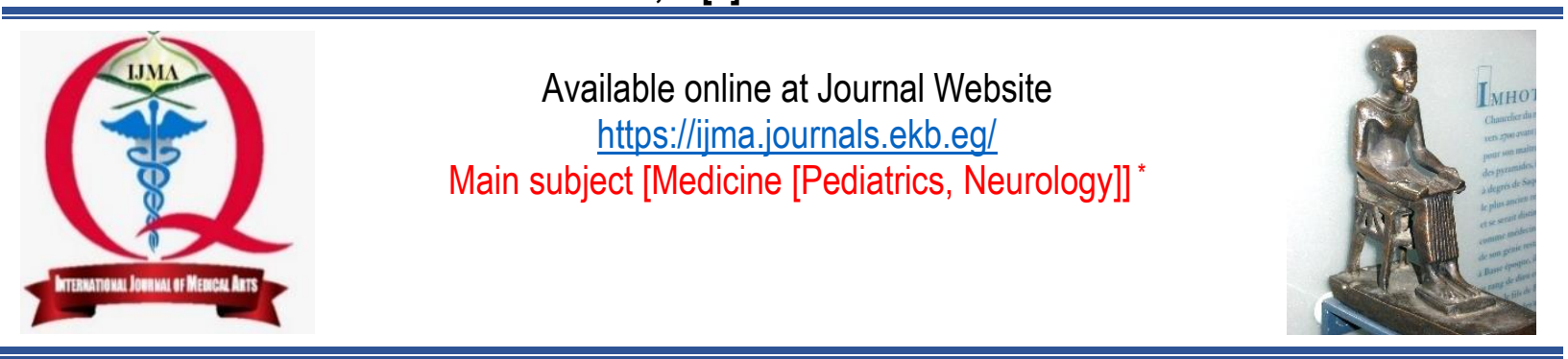

Original article

\title{
Prevalence of Headache in Children with Epilepsy
}

\author{
Sherief Mahmoud Alshazly[1]; Hany Abdel-Hady El-khaleegy[2]
}

Department of Neurology, Damietta Faculty of Medicine, Al-Azhar University, Egypt[1].

Department of Pediatrics, Damietta Faculty of Medicine, Al-Azhar University, Egypt ${ }^{[2]}$.

Corresponding author: Sherief Mahmoud Alshazly

Email: sheriefshazly19@gmail.com

Received at: September 22, 2020; Revised at: October 25, 2020; Accepted at: October 26, 2020

DOI: 10.21608/ijma.2020.43838.1180

\section{ABSTRACT}

Background: Epilepsy is a common pediatric health problem that urges parents to seek medical advice. However, it could be associated with prodromal manifestation [e.g., headache] that the parents usually pass unnoticed. Previous literature is defective regarding the prevalence of headaches among children with epilepsy.

Aim of the work: Estimating the prevalence and characteristics of headaches associated with epilepsy in pediatric populations.

Patients and methods: We included 130 children with epilepsy [study group] and 130 healthy children as a control group. All were selected from Al-Azhar University Hospitals [new Damietta]. An inquiry about headache and its characteristics, especially in relation to seizure attacks, had been performed.

Results: Children with epilepsy had a higher rate of headache when compared to healthy children $[48.5 \%$ versus $22.3 \%$ ]; migraine is the commonest type in the epileptic group and tension-type headache in the control group. In children with epilepsy, headaches were associated with a higher rate of generalized epileptiform activity, increased frequency of seizures, and monotherapy use.

Conclusion: Headache is highly prevalent among children with epilepsy and necessitates proper screening, further investigations, and proper treatment. Future studies to investigate the problem on a wide scale are warranted.

Keywords: Headache; Migraine; Tension headache; Epilepsy; Pediatrics.

This is an open-access article registered under the Creative Commons, ShareAlike 4.0 International license [CC BY-SA 4.0] [https://creativecommons.org/licenses/by-sa/4.0/legalcode.

Please cite this article as: Alshazly SM, El-khaleegy HA. Prevalence of Headache in Children with Epilepsy. IJMA 2021; 3[1]: 905-912. DOI: 10.21608/ijma.2020.43838.1180.

${ }^{*}$ Main subject and any subcategories have been classified according to the research topic. 


\section{INTRODUCTION}

Headache with its different subtypes is very common in pediatrics, with increasing prevalence with the advancement of age. About half of referrals to neurology clinics are due to headache in pediatrics. Unfortunately, the link between headache to different neurological diseases is underestimated by parents. Parents usually hope the pain is relieved, and they seek reassurance that their child's headache is not due to serious intracranial disease [e.g., brain tumor]. The commonest types of headaches among children are migraine and tension-type headache. Other - but rare - causes are cluster headache, idiopathic intracranial hypertension $[\mathrm{ICH}]$, hemicrania continua, and $\mathrm{ICH}$ secondary to the tumor [1]. Epilepsy is one of the commonest neurologic disorders in pediatrics, with incidence rates of 33.3 to 82 cases per 100,000 per year. The highest incidence of seizures is recorded in the first year after birth. Then, it decreases in the teen years. The etiology of pediatric seizures remains unknown in about half of pediatric patients [2]. Epilepsy and headache share many characteristics: both are chronic paroxysmal disorders, common among adult and pediatric populations, with episodic manifestations [3]. Headache is defined as a painful feeling in the head. Different types of headache include migraine, tension-type, and cluster types. Epileptic seizures are brief attacks caused by abnormal excessive synchronized neuronal activity. Epilepsy is defined by a tendency to recurrent unprovoked seizures [4]. Both headache and epilepsy coexist in some patients [5].

Headache associated with epilepsy is common, with $42-51 \%$ incidence in adults with epilepsy. However, in pediatric populations, some parents neglect headaches associated with epilepsy due to other neurological manifestations of epilepsy [e.g., loss of consciousness], and about $36 \%$ reported that they are unaware of headaches associated with epilepsy[6]. The exact prevalence of headaches associated with epilepsy is unknown exactly in our community, and there are no known studies after the extensive search had been reported to deal with such a problem. The type of headache most commonly associated with epilepsy in pediatric patients is not well addressed yet.

\section{AIM OF THE WORK}

The current work aimed to estimate the prevalence and characteristics of headache associated with epilepsy in pediatric patients

\section{PATIENTS AND METHODS}

The current trial was conducted at the Pediatric Neurology and Neurology Departments [Al-Azhar University Hospital, Damietta]. It had been carried out from December 2017 to December 2019]. We included children with a confirmed diagnosis of epilepsy, who were under medical treatment at the time of the inquiry about a headache. Children with known brain disease [e.g., congenital, ischemic, etc..] or recent traumatic brain injury were excluded. Children with their legal guardian were asked about the presence of headache, its characteristics, and relations to their seizures and family history of epilepsy.

The sample size had been justified according to a previous cross-sectional study carried out by Kanemura et al. [7] [seizure-related headache had been reported in $34.7 \%$ of studied children]. Thus, with the desired power of $80 \%$, at a standard normal variation at $5 \%$ type-l error, 130 children were need, according to the following equation:

Sample size $=\left[Z_{1-a^{2}} \times p[1-p]\right] / d^{2}$, where $Z_{1-a}$ stands for standard normal variate [1.96 at $5 \%$ type 1 error], p expected proportion [35\% according to previous study], and $d$ absolute error or precision [5.0\%]. To confirm the association between headache and epilepsy, we included another 130 apparently healthy children, matched for age and sex, as a control group and searched for headache among this group.

In the current study, the headache had been defined as any pain located above the orbitomeatal line. The migraine had been defined as a recurrent attack of headache lasting 1-72 hours. Migraine is characteristically unilateral, pulsating, moderate to severe in intensity, aggravation by routine daily activities, and associated with any single or combination of nausea, photophobia, or phonophobia. Besides, tension-type headache [TTH] was defined as recurrent episodes of headaches lasting minutes to weeks, pressing or tightening quality, mild to moderate intensity, and bilateral. It did not worsen by routine physical 
activity; photophobia or phonophobia may be present, but nausea and vomiting are usually absent [8]. Besides, epilepsy is defined as a chronic neurological disorder characterized by recurrent manifestations [symptoms and signs] of excessive and/or hypersynchronous, usually self-limited activity of neurons in the brain[9].

Seizure-related headache [SRH] may be pre-or postictal [it may precede or follow the manifestations of actual seizure] and occurred within one hour before or after the seizure. The preictal headache had been defined as a headache that began within one hour before a seizure and lasted until its onset. The postictal headache had been defined as a headache occurring immediately after cessation of the attack and lasted no more than an hour or alleviated by anti-epileptic drugs. In addition, inter-ictal headache is defined as a headache that occurred independently of an epileptic attack[10].

For headache, we inquired about the following: its type, onset, relation to seizure, duration, localization, frequency, drugs, and any associated autonomic manifestations. All children in the epileptic group underwent electroencephalogram [EEG] examination and computed tomography.

Data analysis: The collected data had been coded and fed to a personal computer, specifically to statistical package for social science [SPSS] software package to calculate results. Statistical presentation for numerical data included measures of central tendency [mean] and dispersion [standard deviation [SD] and range]. But categorical variables presented as relative frequency and percentages. Groups compared by independent samples $[t]$ or Chi-square tests according to data types. $P<0.05$ had been considered significant. The SPSS version 18 [SPSS Inc., Chicago, USA] had been used to handle all statistical processes.

\section{RESULTS}

In the current work, 130 epileptic children had been included and represented in the study group, and another healthy 130 children were incorporated as a control group. Males represented $61.5 \%$ and $59.2 \%$ of study and control groups, respectively; the child age ranged between 7 and 15 years, with no significant difference between study and control group $[11.97 \pm 2.07$ vs. $11.54 \pm 1.92$ years respectively]. Headache was reported among $48.5 \%$ in the study group and $22.3 \%$ in the control group. Migraine-type headache was the most prevalent among the study group [60.3\%], followed by tension-type headache [22.2\%], while tensiontype headache was the most common among the control group [72.4\% followed by migraine [27.6\%] with a significant difference between study and control groups. Specific to the study group, there was a headache type probably related to drug use [12.7\%], and $4.8 \%$ of headaches could not be specified. The family history of epilepsy was positive among $19.2 \%$ and $9.2 \%$ of the study and control groups, respectively, with a significant difference. The headache time in relation to epilepsy was pre-ictal among $20.6 \%$ of the study group and postictal among $27.0 \%$, and inter-ictal among $52.4 \%$. Finally, epilepsy was generalized among $59.2 \%$, partial with secondary generalization among $10.0 \%$, and partial among $30.8 \%$ [Table 1].

Regarding EEG results among study group, $21.5 \%$ [28 patients] revealed normal results, $48.5 \%$ [63 patients] showed focal epileptiform activity and $30.0 \%$ [39 patients] had generalized or focal slowing.

Searching for factors differentiating headache related to seizures, we identified that seizurerelated headache $[\mathrm{SRH}]$ was significantly associated with younger age [the mean age was $11.89 \pm 2.10$ and $12.86 \pm 1.88$ among SRH when compared to non-SRH subgroups, respectively]. In addition, migraine was significantly increased among the SRH subgroup [60.3\%], while tensiontype headache was significantly increased among the non-SRH subgroup [72.4\%] [Table 2].

In epileptic group, headache was associated with significantly higher percentage of generalized epileptiform activity [ $44.4 \%$ vs $16.4 \%$ ], increased frequency of seizures $[3.77 \pm 1.50$ vs $2.52 \pm 0.70$ time/year], increased use of monotherapy [ $87.3 \%$ vs $62.7 \%$ ], and increased use of carbamazepine and levetriacetam $[68.8 \%, 72.7 \%$ vs $31.3 \%$ and $27.3 \%$ respectively] [Table 3 ]. 
Table [1]: Comparison between study and control groups according to child demographic data, headache and epilepsy characteristics

\begin{tabular}{|c|c|c|c|c|c|}
\hline & & $\begin{array}{l}\text { Study [epileptic] } \\
\qquad[\mathrm{n}=130]\end{array}$ & $\begin{array}{l}\text { Control [non-epileptic] } \\
\qquad[\mathrm{n}=130]\end{array}$ & Test & $P$ value \\
\hline Gender & Male & $80[61.5 \%]$ & $77[59.2 \%]$ & 0.14 & 0.70 \\
\hline & Female & $50[38.5 \%]$ & $53[40.8 \%]$ & & \\
\hline Age [year] & & $11.97 \pm 2.07 ; 7-15$ & $11.54 \pm 1.92 ; 8-15$ & 1.70 & 0.09 \\
\hline Headache & Yes & 63[48.5\%] & $29[22.3 \%]$ & 19.44 & $<0.001^{*}$ \\
\hline & No & $67[51.5 \%]$ & $101[77.7 \%]$ & & \\
\hline Type of & Migraine & $38[60.3 \%]$ & $8[27.6 \%]$ & & \\
\hline headache & Tension type & $14[22.2 \%]$ & $21[72.4 \%]$ & & \\
\hline & Probable drug related & $8[12.7 \%]$ & $0[0.0 \%]$ & 22.40 & 0.001 \\
\hline & Not-specified & $3[4.8 \%]$ & $0[0.0 \%]$ & & \\
\hline Family history & Positive & $25[19.2 \%]$ & $12[9.2 \%]$ & 5.32 & $0.021^{*}$ \\
\hline of epilepsy & Negative & $105[80.8 \%]$ & $118[90.8 \%]$ & & \\
\hline Timing of & Pre-ictal & $13[20.6 \%]$ & & & \\
\hline headache & Post-ictal & $17[27.0 \%]$ & & & \\
\hline & Inter-ictal & $33[52.4 \%]$ & & & \\
\hline Type of & Generalized & $77[59.2 \%]$ & & & \\
\hline epilepsy & Partial & $40[30.8 \%]$ & & & \\
\hline & Partial with secondary generalization & $13[10.0 \%]$ & & & \\
\hline
\end{tabular}

Table [2]: Comparison between headache related to seizures and headache not related to seizures

\begin{tabular}{|c|c|c|c|c|c|}
\hline & & $\begin{array}{c}\mathrm{SRH} \\
{[\mathrm{n}=63]}\end{array}$ & $\begin{array}{c}\text { Non-SRH } \\
{[n=29]}\end{array}$ & Test & $P$ value \\
\hline \multirow[t]{2}{*}{ Gender } & Male & $38[60.3 \%]$ & $19[65.5 \%]$ & \multirow[t]{2}{*}{0.22} & \multirow[t]{2}{*}{0.63} \\
\hline & Female & $25[39.7 \%]$ & $10[34.5 \%]$ & & \\
\hline \multicolumn{2}{|l|}{ Age [year] } & $11.89 \pm 2.10 ; 7-15$ & $12.86 \pm 1.88 ; 10-15$ & 2.13 & $0.036^{*}$ \\
\hline \multirow{4}{*}{$\begin{array}{l}\text { Type of } \\
\text { headache }\end{array}$} & Migraine & $38[60.3 \%]$ & $8[27.6 \%]$ & \multirow{4}{*}{22.46} & \multirow{4}{*}{$<0.001^{*}$} \\
\hline & Tension type & $14[22.2 \%]$ & $21[72.4 \%]$ & & \\
\hline & Probable drug related & $8[12.7 \%]$ & $0[0.0 \%]$ & & \\
\hline & Not-specified & $3[4.8 \%]$ & $0[0.0 \%]$ & & \\
\hline \multirow{2}{*}{$\begin{array}{l}\text { Family history } \\
\text { of epilepsy }\end{array}$} & Positive & $16[25.4 \%]$ & $6[20.7 \%]$ & \multirow[t]{2}{*}{0.24} & \multirow[t]{2}{*}{0.62} \\
\hline & Negative & $47[74.6 \%]$ & $23[79.3 \%]$ & & \\
\hline
\end{tabular}


Table [3]: Factors related to headache in epileptic group

\begin{tabular}{|c|c|c|c|c|c|}
\hline & & $\begin{array}{c}\text { Headache } \\
{[n=63]}\end{array}$ & $\begin{array}{c}\text { No headache } \\
{[n=67]}\end{array}$ & Test & $P$ value \\
\hline \multirow[t]{2}{*}{ Gender } & Male & $38[60.3 \%]$ & $42[62.7 \%]$ & \multirow[t]{2}{*}{0.07} & \multirow[t]{2}{*}{0.78} \\
\hline & Female & $25[39.7 \%]$ & $25[37.3 \%]$ & & \\
\hline \multicolumn{2}{|l|}{ Age [year] } & $11.89 \pm 2.10$ & $12.04 \pm 2.06$ & 0.42 & 0.67 \\
\hline \multirow{2}{*}{$\begin{array}{l}\text { Family history } \\
\text { of epilepsy }\end{array}$} & Positive & $16[25.4 \%]$ & $9[13.4 \%]$ & \multirow[t]{2}{*}{2.99} & \multirow[t]{2}{*}{0.08} \\
\hline & Negative & $47[74.6 \%]$ & $58[86.6 \%]$ & & \\
\hline \multirow[t]{3}{*}{ EEG } & Normal & $4[6.3 \%]$ & $24[35.8 \%]$ & \multirow[t]{3}{*}{21.60} & \multirow[t]{3}{*}{$<0.001^{*}$} \\
\hline & Focal epileptiform activity & $31[49.2 \%]$ & $32[47.8 \%]$ & & \\
\hline & Generalized epileptiform activity & $28[44.4 \%]$ & $11[16.4 \%]$ & & \\
\hline \multirow{3}{*}{$\begin{array}{l}\text { Type of } \\
\text { epilepsy }\end{array}$} & Generalized & $40[63.5 \%]$ & $37[55.2 \%]$ & \multirow[t]{3}{*}{0.97} & \multirow[t]{3}{*}{0.61} \\
\hline & Partial & $17[27.0 \%]$ & $23[34.3 \%]$ & & \\
\hline & Partial with secondary generalization & $6[9.5 \%]$ & $7[10.4 \%]$ & & \\
\hline \multicolumn{2}{|c|}{ Seizure frequency /last year } & $3.77 \pm 1.50 ; 1-7$ & $2.52 \pm 0.70 ; 1-5$ & 6.14 & $<0.001^{*}$ \\
\hline \multirow[t]{2}{*}{ Number of AEDs } & Drug combinations & $8[12.7 \%]$ & $25[37.3 \%]$ & \multirow[t]{2}{*}{10.38} & \multirow[t]{2}{*}{$0.001^{*}$} \\
\hline & Monotherapy & $55[87.3 \%]$ & $42[62.7 \%]$ & & \\
\hline \multirow[t]{5}{*}{ Type of drugs } & Sodium valproate [54] & $25[46.3 \%]$ & $29[53.7 \%]$ & \multirow[t]{5}{*}{16.09} & \multirow[t]{5}{*}{$0.003^{*}$} \\
\hline & Carbamazepine [32] & $22[68.8 \%]$ & $10[31.3 \%]$ & & \\
\hline & Levetiracetam [11] & $8[72.7 \%]$ & $3[27.3 \%]$ & & \\
\hline & Sodium valproate + Levetiracetam [16] & $3[18.8 \%]$ & $13[81.3 \%]$ & & \\
\hline & Carbamazepine+ Levetiracetam [17] & $5[29.4 \%]$ & $12[70.6 \%]$ & & \\
\hline
\end{tabular}

\section{DISCUSSION}

The current study revealed that children with epilepsy had a significantly higher rate of headaches than healthy children $[48.5 \%$ versus $22.3 \%$; migraine is the commonest type associated with epilepsy, while tension-type headache was the most common among healthy children.

In addition, headaches were developed in younger epileptic children, and the high frequency of seizures significantly increased in patients with headaches in epileptic groups. Furthermore, the inter-ictal headache was the most common affecting more than half of included children [52.4\%]; children who reported headaches had significantly higher abnormal changes on EEG examination, and headaches were usually associated with monotherapy [specifically with carbamazepine and levtriracetam].

The estimated incidence of headache associated epilepsy is comparable to a recent metaanalysis of Duko et al.[11] The prevalence of headaches is high [48.4\%] among patients with epilepsy, which require appropriate screening and proper treatment.

In their cross-sectional study, Kanemura et al.,[] included a total of 98 Japanese children [ 43 males and 55 females; age range: $5-18$ years]. Of this group of 98 patients, 74 [75.5\%] had partial seizures, and 24 [24.5\%] had generalized seizures. Both sex distribution and type of seizures are different than the current work.

The difference could be explained by the different sample sizes [here, we included 130 children with epilepsy]. In addition, the ethnic variation could explain the difference. Besides, they reported a lower rate of headache associated with epilepsy [34.7\%]. However, the prevalence of headaches among children in the current study lies within the reported prevalence among adult populations in previous literature [37 to $51 \%]^{[12]}$.

On the other side, the current study results are comparable to those reported by Al-Gethami et al. ${ }^{[3]}$ who reported that, in Saudi children included in their study, 65 [45.7\%] patients had headaches compared with $3 / 153$ [2\%] in the control group. They also had gender and age distribution comparable to the current work. They reported that 
82 children were males [57.7\%], and the overall average age was $10.7 \pm 3.1$ years.

Unlike the current work, Al-Gethami et al. [3] performed neuroimaging studies on all children included in their study and reported that $21 \%$ of them had abnormal results [e.g., focal cortical dysplasia and mild ischemic brain insult]. Their results coincide with the current work regarding the most common type of headache among children with epilepsy except an increased percentage of unclassified type. They reported that migraine was reported among $44.6 \%$, 18.4\% had tension-type headaches, and $36.9 \%$ had an unclassified type.

The current prevalence of headache among epileptic children is comparable to the results of Yamane et al.[13] who reported a prevalence rate of $46 \%$ among children with epilepsy.

On the other side, a low incidence of $11.4 \%$ had been reported by Papavasiliou et al.[14] among epileptic children reported headache.

In adult populations with epilepsy, Wang et al. ${ }^{[15]}$ reported a prevalence of $12.5 \%$ of headache among a large sample size consisted of 1109 patients.

Besides, Mainieri et al. ${ }^{[16]}$ reported a prevalence of $53.9 \%$ of headaches in patients with epilepsy.

To explain the pathophysiology responsible for headaches and epilepsy, migraine was the most extensively studied type. It had been reported that both migraine attacks and epilepsy could be triggered by cellular excitability of the cortex [neuronal overactivity]. It eventually results in pain in migraine, but in epilepsy, it could be further extended to recruit other neurons with subsequent firing in a rhythmic pattern [epilepsy]. Confirming this assumption is the fact that migraine aura may act as a trigger for epilepsy. Thus, headache and its aura could constitute part of the epileptic attack[17].

Some forms of epilepsy and migraine share the same genetic origin, and some AEDs are effective in treating migraine[18].
Consistent with the results of the current work, Al-Gethami et al.[3] reported in the EEG of 141 patients. Normal results were reported in $41.8 \%$, and $51.8 \%$ showed epileptiform activity [either focal or generalized interictal discharges] with a predominance of generalized discharges.

In the current work, we defined the timing of headaches as either pre-ictal, postictal, or interictal, and most patients had inter-ictal type [52.4\%].

Yamane et al.[13] reported that $60.0 \%$ of headaches were inter-ictal, while Hofstra et al.[19] reported that $70 \%$ of their adult patients had an inter-ictal headache. On the other side, Kanemura et al. ${ }^{[7]}$ reported a higher prevalence of postictal headache [82\%].

Consistent with the current work results, Ottman and Lipton ${ }^{[20]}$ reported a high rate of migraine headache in patients with epilepsy compared to their first relative or control group [migraine was two-folds as in the control group].

Migraine was reported among $43.5 \%$ and followed by tension-type headache among $17.4 \%$ in the study carried out by Yamane et al.[13].

Other researchers reported an increased incidence of migraine among different specific types of epilepsy [21].

There was a significant increase in monotherapy in children with epilepsy, and monotherapy was significantly associated with the development of headaches in the current work.

Kanemura et al. ${ }^{[7]}$ reported that $70.6 \%$ of their patients with seizure associated headache were treatment by monotherapy, which is comparable to the current results. However, they did not obtain a significant association between monotherapy and incidence of seizure-associated headache, and this could be explained by the small number of patients who reported headache in their study [34 patients].

In adult populations, an Egyptian study from Upper Egypt carried by Sayed et al.[22] revealed that headache associated epilepsy is significantly 
associated with female gender, younger age, focal rather than generalized epilepsy, early onset of epilepsy [mainly in childhood-onset epilepsy], longer duration of epilepsy, poly-therapy, high frequency of seizures/year, and increased EEG abnormalities. These results are quite different than the current study and may reflect the difference between adult and pediatric populations. An interesting finding in that study is the association between increased headache and early onset of epilepsy, especially in children [ $13.90 \pm 7.92$ years in patients with headache and $24.64 \pm 6.94$ years in those without headache].

Mameniskiene et al.[23] as in the current work, reported no association between headacheassociated with epilepsy and patient age or gender. However, others reported increased headaches in younger females[15].

The current study's strength point is the justified sample size, strict inclusion criteria, and the presence of the control group, which confirms the association between headache and epilepsy. Besides, it may be the first study to deal with such a topic in Damietta Governorate; actually, we could not identify other similar studies in Egypt after an extensive search, especially in pediatric populations. Finally, a surprising finding was the high rate of headache among healthy children, which needs further investigation.

In short, the current work revealed a high prevalence of headache among epileptic children, with migraine as a dominant form. It could be considered, and special care should be exerted in the future and directed to early detection and intervention.

Financial and Non-financial Relationships and Activities of Interest

None

\section{REFERENCES}

1. Kelly M, Strelzik J, Langdon R, DiSabella M. Pediatric headache: overview. Curr Opin Pediatr. 2018 Dec; 30 [6]: 748-754. [DOI: 10.1097/MOP.0000000000000 688].
2. Fine A, Wirrell EC. Seizures in Children. Pediatr Rev. 2020 Jul; 41[7]:321-347. [DOI: 10.1542/pir.2019-0134].

3. Al-Gethami H, Alrifai MT, AIRumayyan A, AlTuwaijri W, Baarmah D. The comorbidity of headaches in pediatric epilepsy patients: How common and what types? Neurosciences [Riyadh]. 2019 Oct; 24[4]: 284289. [DOI: 10.17712/nsj. 2019.4. 20190043]

4. Fisher RS, van Emde Boas W, Blume W, Elger C, Genton $\mathbf{P}$, Lee $\mathbf{P}$, et al. Epileptic seizures and epilepsy: definitions proposed by the International League Against Epilepsy [ILAE] and the International Bureau for Epilepsy [IBE]. Epilepsia 2005; 46: 470472. [DOI: 10.1111/j.0013-9580.2005. 66104.x].

5. Haut SR, Bigal ME, Lipton RB. Chronic disorders with episodic manifestations: focus on epilepsy and migraine. Lancet Neurol 2006; 5: 148-157. [DOI: 10.1016/ S1474-4422 [06]70348-9].

6. Parisi $\mathbf{P}$. Why is migraine rarely, and not usually, the sole ictal epileptic manifestation? Seizure 2009; 18: 309312. [DOI: 10.1016/j.seizure.2009.01.010].

7. Kanemura H, Sano F, Ishii S, Ohyama T, Sugita K, Aihara M. Characteristics of headache in children with epilepsy. Seizure. 2013 Oct;22[8]:647-50. [DOI: 10.1016/j.seizure.2013.04.022].

8. Headache Classification Committee of the International Headache Society [IHS]. The International Classification of Headache Disorders, 3rd edition [beta version]. Cephalalgia. $2013 \mathrm{Jul}$; 33[9]:629-808. [DOI: 10.1177/0333102413485658].

9. Berg AT, Berkovic SF, Brodie MJ, Buchhalter J, Cross JH, van Emde Boas W, et al. Revised terminology and concepts for organization of seizures and epilepsies: report of the ILAE Commission on Classification and Terminology, 2005-2009. Epilepsia. 2010 Apr; 51 [4]: 676-85. [DOI: 10.1111/j.15281167.2010.02522.x].

10. Kasteleijn-Nolst Trenité DG, Verrotti A, Di Fonzo A, Cantonetti L, Bruschi R, Chiarelli F, Villa MP, Parisi P. Headache, epilepsy and photosensitivity: how are they connected? J Headache Pain. 2010 Dec;11 [6]: 469-76. [DOI: 10.1007/ s10194-010-0229-9].

11. Duko B, Ayalew M, Toma A. The epidemiology of headaches among patients with epilepsy: a systematic review and meta-analysis. J Headache Pain. 2020 Jan 10; 21 [1]: 3. [DOI: 10.1186/s10194020-1074-0].

12. Ito $M$, Adachi $\mathbf{N}$, Nakamura $F$, Koyama T, Okamura $T$, Kato $M$, et al. Characteristics of postictal headache in patients with partial epilepsy. Cephalalgia. 2004; 24 [1]: 23-8. [DOI: 10.1111/j.1468-2982.2004.00628.x].

13. Yamane LE, Montenegro MA, Guerreiro MM. Comorbidity headache and epilepsy in childhood. 
Neuropediatrics. 2004 Apr; 35 [2]: 99-102. [DOI: 10.1055/s-2004-815831].

14. Papavasiliou AS, Bregianni M, Nikaina I, Kotsalis C, Paraskevoulakos E, Bazigou H. Pediatric Headache and Epilepsy Comorbidity in the Pragmatic Clinical Setting. Neuropediatrics. 2016 Apr; 47[2]:107-11. [DOI: 10.1055/s-0036-1571799].

15. Wang XQ, Lang SY, He MW, Zhang X, Zhu F, Dai W, et al. High prevalence of headaches in patients with epilepsy. J Headache Pain. 2014 Nov 4;15[1]:70. [DOI: 10.1186/1129-2377-15-70].

16. Mainieri G, Cevoli S, Giannini G, Zummo L, Leta C, Broli M, et al. Headache in epilepsy: prevalence and clinical features. J Headache Pain. 2015; 16:556. [DOI: 10.1186/s10194-015-0556-y].

17. Nye BL, Thadani VM. Migraine and epilepsy: review of the literature. Headache. 2015 Mar;55[3]:359-80. [DOI: 10.1111/head.12536].

18. Toldo I, Perissinotto E, Menegazzo F, Boniver C, Sartori S, Salviati L, et al. Comorbidity between headache and epilepsy in a pediatric headache center. J Headache Pain. 2010 Jun;11[3]:235-40. [DOI: 10.1007/s10194-010-0191-6].
19. Hofstra WA, Hageman G, de Weerd AW. Periictal and interictal headache including migraine in Dutch patients with epilepsy: a cross-sectional study. Epilepsy Behav. 2015; 44:155-8. [DOl: 10.1016/j.yebeh.2014.12.025]

20. Ottman R, Lipton RB. Comorbidity of migraine and epilepsy. Neurology. 1994 Nov; 44[11]:2105-10. [DOI: 10.1212/wnl.44.11.2105].

21. Kelley SA, Hartman AL, Kossoff EH. Comorbidity of migraine in children presenting with epilepsy to a tertiary care center. Neurology. 2012 Jul 31;79[5]:46873. [DOI: 10.1212/WNL.0b013e3182617113].

22. Sayed MA, Ibrahim HK, Bekhit AS, Thabit MN, Abdelmomen M. Clinical Characteristics of Headache in Egyptian Patients with Idiopathic Epilepsy. Journal of Behavioral and Brain Science 2019; 9: 144-153 [DOI: 10.4236/jbbs.2019.93012]

23. Mameniskiene R, Karmonaite I, Zagorskis R. The burden of headache in people with epilepsy. Seizure. 2016; 41:120-6. [DOI:10.1016/j.seizure.2016.07.018]. 


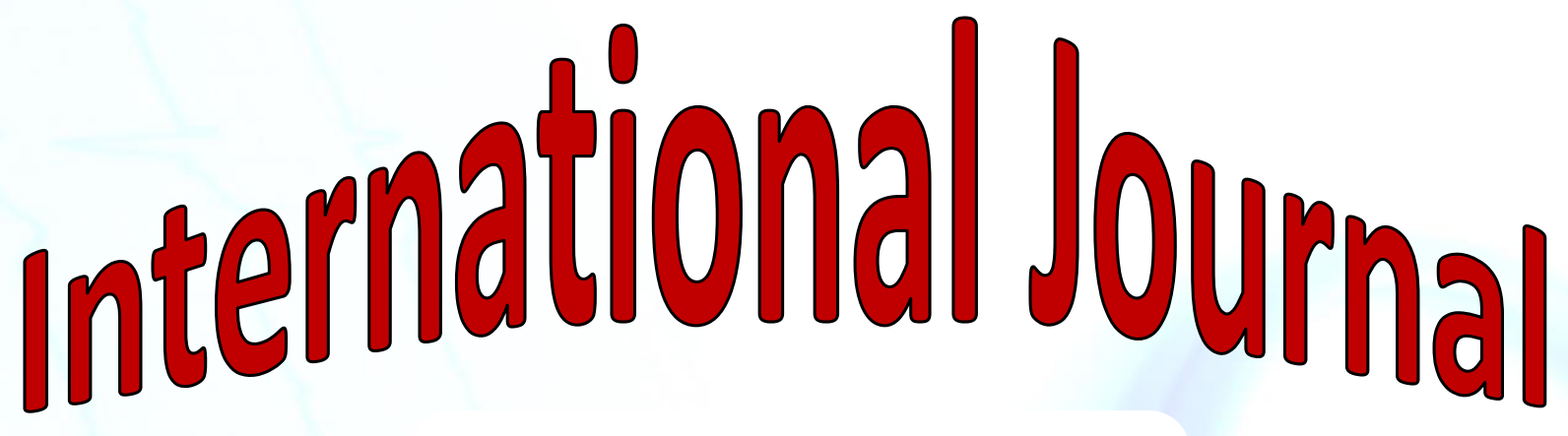

https://ijma.journals.ekb.eg/

Print ISSN: 2636-4174

Online ISSN: 2682-3780

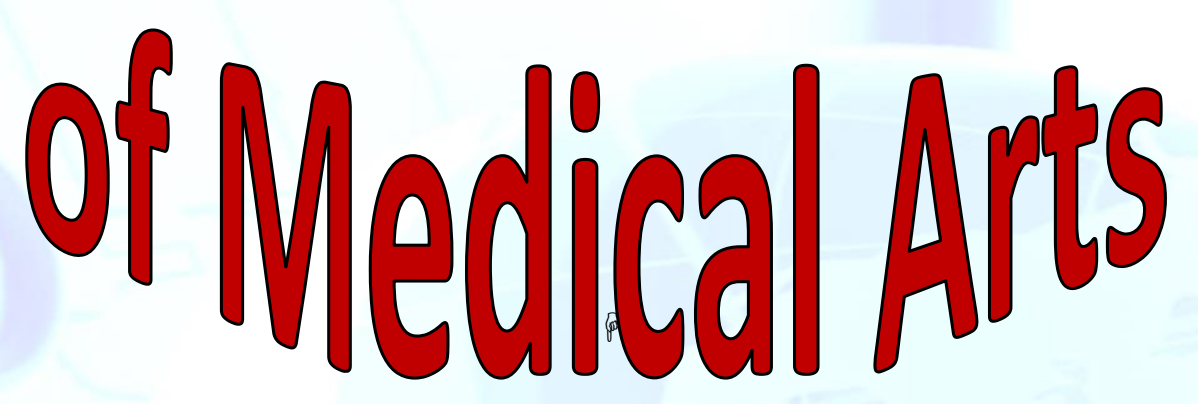

